\title{
LOS RECURSOS DEL DEFENSOR DEL PUEBLO ANTE EL TRIBUNAL CONSTITUCIONAL. UNA REVISIÓN
}

\author{
IGNACIO TORRES MURO \\ Catedrático de Derecho Constitucional \\ Universidad Complutense de Madrid
}

SUMARIO

I. Introducción.

II. Los recursos de inconstitucionalidad del Defensor del Pueblo.

III. Los recursos de amparo del Defensor del Pueblo.

IV. Otros pleitos en los que ha estado involucrada la institución.

V. Un resultado pobre, pero con algunos momentos de gloria.

VI. Conclusión. Un balance de la legitimación del Defensor del Pueblo ante el Tribunal Constitucional.

\section{INTRODUCCIÓN}

El propósito de este artículo no es el de discutir los aspectos generales, y el debate teórico, sobre la legitimación que la Constitución, la Ley Orgánica

1 La elaboración de este trabajo no hubiera sido posible sin la ayuda del personal de las bibliotecas del Tribunal Constitucional, y de la Facultad de Derecho de la Universidad Complutense, que han respondido con gran amabilidad a mis demandas. Debo también agradecer su disponibilidad a mi amigo, y compañero del cuerpo de letrados del Tribunal, Ignacio Borrajo, que me ayudó a conseguir materiales varios. Asimismo, el profesor Sánchez Saudinós, jefe del gabinete del Adjunto segundo del Defensor del Pueblo, me facilitó documentos de difícil acceso. Ni que decir tiene que le estoy muy agradecido. Las abreviaturas son las habituales: ATC, Auto del Tribunal Constitucional; CE, Constitución española de 1978; EAC Estatuto de Autonomía de Cataluña de 2006; LODP, Ley Orgánica del Defensor del Pueblo; LOTC, Ley Orgánica del Tribunal Constitucional; ONU, Organización de Naciones Unidas; STC, Sentencia del Tribunal Constitucional; TC, Tribunal Constitucional. 
del Tribunal Constitucional y la Ley Orgánica del Defensor del Pueblo conceden a esta institución para intervenir en los procesos constitucionales, sino hacer algo mucho más prosaico, pero creemos que igualmente útil. Se trata de repasar las circunstancias en las que dicha institución ha hecho uso de esos poderes, y cuales han sido los resultados obtenidos. No cabe duda de que el examen de esta práctica aportará datos que contribuirán a hacerse una opinión sobre si los mismos han sido utilizados correctamente, e incluso si están justificados, y son verdaderamente operativos, pero insistimos en que no es nuestro propósito entrar de lleno en una discusión de la que se van a ocupar otros autores en esta misma revista, y sobre la que ya dijimos algo, que sustancialmente mantenemos, hace no mucho tiempo ${ }^{2}$.

Dado que son dos los procesos constitucionales —el recurso de inconstitucionalidad y el recurso de amparo- en los que puede participar como recurrente el Defensor del Pueblo, de acuerdo con los arts. 162.1 a) y b) CE, 32.1 b) y 46.1 a) y b) LOTC, y 29 LODP, en el presente estudio nos ocuparemos sucesivamente de los resultados de estas dos legitimaciones, destacando ya de antemano que el uso de las mismas por dicho órgano constitucional puede calificarse de prudente. El primer ocupante del mismo ha hablado de "la mesura con que nuestra institución ha procurado actuar en esta delicada vertiente de sus funciones ${ }^{3}$. Por ello, las dimensiones de los materiales producidos son abarcables en el marco de un artículo como éste, aunque también nos veamos obligados a un lógico esfuerzo de síntesis para mantenernos en unos límites razonables. Serán, por eso, frecuentes las remisiones a datos, y jurisprudencia, que se encuentran con facilidad.

Para completar la revisión jurisprudencial, hemos incluido también un apartado sobre algunos procesos en los que, aunque el Defensor del Pueblo no participara como actor, sí se vio afectada la delimitación de los poderes de éste, y de las figuras afines de las Comunidades Autónomas.

\section{LOS RECURSOS DE INCONSTITUCIONALIDAD DEL DEFENSOR DEL PUEBLO.}

\section{II.1. SUbVENCIONES A LOS SINDICATOS MÁS REPRESENTATIVOS} (SSTC 20/1985, DE 14 DE FEBRERO, 26/1985, DE 22 DE FEBRERO, Y 72/1985, DE 13 DE JUNIO)

Se alzó el Defensor del Pueblo en estos casos contra la política de prever en los Presupuestos generales del Estado que las subvenciones a los sindica-

2 Veáse nuestro libro La legitimación en los procesos constitucionales, Reus, Madrid, 2007, págs. 41 y ss. y 224 y ss.

3 J. RUIZ-GIMÉNEZ en Presentación a Defensor del Pueblo, Recursos ante el Tribunal Consittucional 1983-1987, Defensor del Pueblo, Madrid, 1987, pág. VI. 
tos para la realización de actividades socioculturales, promoción de los trabajadores, organización de actividades de carácter formativo, y otras, dentro de los fines de aquellos, fueran a parar a las "Centrales sindicales más representativas, de conformidad con la disposición adicional sexta de la Ley 8/1980, de 10 de marzo, del Estatuto de los Trabajadores, en proporción a su representatividad, según los resultados globales a que hace referencia el art. 75.5 de dicha Ley»[capítulo 04, art. 48, concepto 483, del anexo III, sección 19 (Trabajo y Seguridad Social), servicio 01, de la Ley 9/1983, de 13 de julio, de Presupuestos Generales del Estado para 1983]. Dicha norma fue prevista también en los Presupuestos para 1984 y 1985.

La respuesta a las correspondientes impugnaciones del Defensor del Pueblo se dio en las sentencias citadas, de las que nos interesa, sobre todo, la primera, puesto que en las dos últimas el Tribunal se limita a reproducir doctrina. En la STC 20/1985, de 14 de febrero, en efecto, nuestra Corte Constitucional sostiene que la finalidad de la subvención es tan amplia, y puede cumplirse con actividades tan diversas, que no permite sostener que para su consecución sea un criterio objetivo y razonable el de atribuirla en exclusiva a las Centrales más representativas, como medida proporcionada. Además, apunta que podríamos estar ante una presión indirecta para afiliarse a un determinado sindicato, al situar a aquellas en una posición superior a las demás para ofrecer mejores servicios a los trabajadores, incompatible con la libertad reconocida en el art. 28.1 CE. La conclusión es que ha habido una vulneración de dicha norma constitucional y debe, por, tanto, suprimirse la mención en el precepto de las centrales sindicales más representativas. Firma un voto particular el magistrado Rubio Llorente por considerar constitucionalmente inaceptable la totalidad de la partida presupuestaria, y no sólo el inciso que de ella se elimina. Advierte a los riesgos de un Tribunal que no respete las opciones del legislador, pero afirma que está fuera de toda discusión la necesidad de que sea una auténtica Ley, esto es, norma jurídica que delimite supuestos de hecho y señale consecuencias jurídicas, la que resuelva estos temas, y no una mera partida presupuestaria.

\section{II.2. CONTRA LA REgUlación DE LOS DERECHOS Y LIBERTADES DE LOS EXTRANJEROS (STC 115/1987, DE 7 DE JULIO)}

Una sentencia especialmente importante de las que han sido producto de un recurso de inconstitucionalidad del Defensor del Pueblo es la 115/1987, de 7 de julio, acerca de algunos de los aspectos de la Ley Orgánica 7/1985, de 1 de julio, sobre derechos y libertades de los extranjeros en España, antecedente de otras regulaciones más recientes, también muy polémicas. El recurso se dirigía, en primer lugar, contra el art. 26.2 de la misma en el que se regulaba la intervención judicial en el internamiento de los extranjeros en los centros correspondientes. El Tribunal, en este caso, hace una interpretación conforme a la Constitución del precepto, y afirma, contra lo que argumentaba 
el Defensor, que no puede considerarse dicho internamiento ni de carácter administrativo, ni sin las garantías de fondo y forma que eviten su carácter arbitrario.

Los derechos de reunión y asociación de los extranjeros son el siguiente objeto del recurso. Aquí el Defensor tiene más éxito, pues consigue que se declare la inconstitucionalidad de la previa autorización de las reuniones de extranjeros, dado que, dice el Tribunal, cuando ese acto habilitante es preciso en todo caso, se condicionan hasta tal punto las facultades que lo integran, que el pretendido derecho muda de naturaleza, y no puede ser reconocido como tal. Además, también logra la expulsión del ordenamiento de un artículo de la Ley Orgánica que permitía al Consejo de Ministros suspender las actividades de las asociaciones de extranjeros, desde el momento en que el mismo, para el TC, establecía una intervención administrativa que resultaba totalmente incompatible con la garantía al derecho de asociación reconocida en el art. 22.4 CE, consistente, como se sabe, en que debe intervenir el juez.

De ambas decisiones disintieron, en un voto particular, los magistrados Rubio Llorente, Tomás y Valiente, y García-Mon, sosteniendo que el legislador puede configurar esas libertades públicas, cuando se trate de extranjeros, y de acuerdo con el art. $13 \mathrm{CE}$, del modo que juzgue más adecuado, excluyendo de su disfrute a conjuntos determinados genéricamente, o reduciendo su contenido a sólo una fracción del que esa misma libertad tiene cuando se predica de los españoles. Por otra parte, las restricciones previstas en la ley encajan holgadamente en las que los Tratados internacionales autorizan, siendo estos los únicos límites que indirectamente la Constitución impuso a su libertad de configuración.

También admitió el Tribunal los razonamientos del Defensor en lo que se refería a la pretensión de la ley de que en ningún caso pudiera acordarse la suspensión de las resoluciones administrativas adoptadas de conformidad con lo establecido en la misma, pretensión que fue declarada inconstitucional por lesiva del derecho a la tutela judicial efectiva, y porque los valores que dicha medida pretendía salvaguardar pueden ser valorados por los tribunales al adoptar, o no, la suspensión.

Como vemos, esta intervención del Defensor del Pueblo, en una materia que ha venido adquiriendo cada vez más trascendencia desde entonces, resultó especialmente importante, y responde perfectamente a su papel en defensa de los derechos fundamentales de todos.

\section{II.3. SOBRE LA OBJECIÓN DE CONCIENCIA (STC 160/1987, DE 27 DE OCTUBRE)}

En el caso resuelto por la sentencia citada en el encabezamiento de este epígrafe, el Defensor del Pueblo interpuso recurso de inconstitucionalidad contra la totalidad, y diversos artículos, de la Ley 48/1984, de 26 de diciembre, reguladora de la objeción de conciencia y de la prestación social sustitutoria, 
y contra algunas normas de la Ley Orgánica 8/1984, de 26 de diciembre, reguladora del régimen de recursos y régimen penal en materia de objeción de conciencia y prestación social sustitutoria. Obtuvo un rotundo fracaso, pues sus argumentaciones fueron desestimadas en su totalidad, rotundo fracaso paliado por la existencia de algunos votos particulares que, en parte, le daban la razón.

En primer término, el Tribunal afirmó que el derecho a la objeción de conciencia, aún en la hipótesis de estimarlo fundamental, tesis que la mayoría no admite, pero sí el magistrado de la Vega Benayas en su voto particular, no está sujeto a la reserva de Ley Orgánica, por no estar incluido en la Sección Primera, del Capítulo II del Título I de la CE, de modo que su desarrollo legislativo mediante ley ordinaria no es contrario al art. 81.1 CE.

Contra lo sostenido por el Defensor, el TC entiende que no basta que el objetor se declare como tal para que se le reconozca esta condición, porque el fuero de la conciencia ha de conciliarse con el fuero social o colectivo, momento en el que la intervención del Consejo Nacional de Objeción de Conciencia es importante en una actuación no constitutiva, pero sí declarativa. Con los mismos razonamientos se convalida la impugnada previsión de que el Consejo pueda pedir documentaciones complementarias o testimonios, pues el derecho a la objeción de conciencia no es incondicionado, y está necesitado de expresión, constatación y reconocimiento. También discrepa aquí el magistrado de la Vega, y su compañero García-Mon.

Tampoco considera el Tribunal aceptable el reproche que el recurso hace, tanto a la forma de la prestación social sustitutoria, como a su duración más prolongada que la del servicio militar. No existe la discriminación alegada, pues no nos hallamos ante supuestos de hechos sustancialmente iguales. La distinción está justificada, y tiene un fundamento objetivo y razonable. En el sentido del recurso vuelve a manifestarse el magistrado de la Vega, acompañado de García-Mon, y Rodríguez-Piñero.

En cuanto a los regímenes disciplinarios y penal, el TC sostiene que no cabe hablar de que los objetores de conciencia sean discriminados en relación con los funcionarios civiles, y recuerda que las normas penales de las leyes citadas ya habían sido expulsadas del ordenamiento al resolverse el recurso. $\mathrm{Ni}$ el término de comparación es correcto, ni se da la arbitrariedad que se denuncia. Vuelve aquí el magistrado de la Vega ha expresar su discrepancia.

En el problema de derecho transitorio de los objetores que estaban esperando a que se aprobara la ley para cumplir la prestación, el Tribunal convalida también los preceptos de las leyes (Disposiciones transitorias) al razonar que no contienen normas retroactivas que restrinjan derechos individuales, con infracción del art. 9.3 CE, como sostenía el Defensor.

El balance, como vemos, es una derrota absoluta de las pretensiones del Defensor del Pueblo, que vio como el recurso era desestimado en su totalidad. 
II.4. Dos Desistimientos (Presupuestos navarros; ATC 636/1985, De 26 de SePtiembre; y Colegio oficial de Periodistas de Cataluña; ATC 812/1988, DE 21 DE JUNIO)

En dos recursos de inconstitucionalidad ha sido aceptado por el Tribunal Constitucional el desistimiento del Defensor del Pueblo. En el primero de ellos en el tiempo combatía este órgano el inciso "contando únicamente a estos efectos aquellas Centrales Sindicales que hayan alcanzado el 10 por 100 de los delegados de personal y miembros de Comités de Empresa" contenido en la disposición adicional decimotercera de la Ley Foral 21/1984, de 29 de diciembre, de Presupuestos Generales de Navarra para el ejercicio de 1985. Dicho inciso fue modificado por el art. 1 de la Ley Foral 10/1985, de 12 de junio, de modo que quedó sin objeto el proceso constitucional y el Defensor desistió de su pretensión, lo que llevó al Tribunal (ATC 636/1985, de 26 de septiembre) a dar por terminado aquél, con el archivo de las actuaciones.

En el segundo (ATC 812/1988, de 21 de junio) se da por desistido al Defensor del Pueblo de la prosecución del recurso de inconstitucionalidad interpuesto contra el art. 1 de la Ley 22/1985, de 8 de noviembre, del Parlamento de Cataluña, de creación del Colegio Profesional del Periodistas de Cataluña, en cuanto establece "que agrupará a todos los periodistas que ejerzan la profesión en el territorio de Cataluña", y las Disposiciones adicional y transitoria primera, en cuanto confirman dicha imperatividad de colegiación, dado que el mismo ha sido modificado por la Ley catalana $1 / 1988$, de 26 de febrero, en la que se da un carácter claramente voluntario a la misma.

\section{II.5. El ReCARGo Fiscal MAdRILEÑO (STC 150/1990, DE 4 DE OCtubre)}

En compañía de cincuenta y cuatro Diputados del Grupo Parlamentario Popular, el Defensor del Pueblo presentó en su momento un recurso de inconstitucionalidad contra la Ley de la Comunidad de Madrid 15/1984, de 19 de diciembre, del Fondo de Solidaridad Municipal, y concretamente contra la regulación en la misma de un recargo del Impuesto sobre la Renta de las Personas Físicas, porque consideraba que vulneraba los principios constitucionales de seguridad jurídica y de no confiscación. Respecto al primer problema el Tribunal sostiene que no cabe admitir, como pretende el recurrente, que se infringe el principio de seguridad jurídica cuando un texto normativo no se plantea, y resuelve por sí mismo de modo explícito, todos los problemas que puede suscitar su aplicación. No obstante la relativa imprecisión de la norma impugnada, es posible concluir que sus problemas de interpretación y aplicación pueden encontrar fácil solución en el marco del ordenamiento vigente. Por otra parte, recuerda que no existe una prohibición constitucional de la 
legislación tributaria retroactiva y que, en el caso concreto, la aplicación de la ley se suspendió por una ley posterior.

En cuanto al alcance confiscatorio del recargo, lesivo del art. $311.1 \mathrm{CE}$, el TC afirma que el mismo (3 por 100 en la cuota líquida del Impuesto sobre la Renta) respeta los principios de igualdad, progresividad y capacidad contributiva, y tanto por su cuantía como por la materia imponible que grava y, en último término, por la finalidad que persigue, no infringe el principio de justicia tributaria, ni por lo mismo cabe reprocharle alcance confiscatorio, imputación ésta que debe ser rechazada. El fallo consistió en la desestimación del recurso. Los votos particulares formulados (Rubio Llorente, Rodríguez-Piñero, y Gabaldón) no se refieren a los problemas planteados por el Defensor.

\section{II.6. Reglamento y Ley Orgánica en la Regulación de la actividad SINDICAL EN LOS ESTABLECIMIENTOS MILITARES (STC 101/1991, DE 13 DE MAYO)}

Recurre en este caso el Defensor del Pueblo contra el párrafo segundo de la Disposición adicional tercera de la Ley Orgánica de Libertad Sindical (1985) porque, al remitir a la determinación reglamentaria "lo que haya de entenderse por establecimientos militares", a los efectos de restricción de dicha libertad sindical, vulnera el art. 81.1 CE.

El Tribunal desestima el recurso, afirmando que está incluida la materia sobre la que se produce la habilitación normativa en el ámbito de la reserva de ley orgánica, dado que afecta directamente a la libertad sindical, pero que la interpretación del Defensor del precepto es demasiado literal, y que es preciso poner al mismo en conexión con otras normas del ordenamiento positivo que se refieren a la misma materia, de modo que resulta fácil establecer que la finalidad que persigue la ley impugnada al prohibir la actividad sindical en el interior de los "establecimientos militares" es la preservación de la neutralidad sindical de las Fuerzas Armadas, y así se deduce inmediatamente de las normas que regulan materias conexas dentro de la ordenación jurídica de las mismas.

\section{II.7. La CEsión De BIENES Del Patrimonio Sindical Acumulado (STC 75/1992, DE 14 DE MAYO)}

De nuevo en esta sentencia el Tribunal desestima el recurso del Defensor del Pueblo, que se dirigía contra el inciso "con preferencia de quienes ostenten la condición de más representativos con arreglo" a la Ley Orgánica de Libertad Sindical "y el resto del ordenamiento jurídico", contenido en el art. 3 de la Ley 4/1986, de 8 de enero, de cesión de bienes del Patrimonio Sindical Acumulado, artículo que determina los sindicatos de trabajadores y asocia- 
ciones empresariales destinatarios de la cesión de los bienes y derechos integrados en dicho Patrimonio.

El TC sostiene, en primer lugar, que el favorecimiento a determinados sindicatos, y la eventual incidencia negativa sobre los sindicatos desfavorecidos, consecuencia inevitable de la propia acción promocional, es conforme con la libertad sindical, puesto que a los sindicatos afectados no se les impide dotarse de medios para desenvolver la actividad que les es propia, ni se les restringen sus derechos de acción, ni se les impide el acceso a la condición de mayoritarios, a través de la participación en el proceso electoral en las empresas que tienen abierto, y en donde además la presencia sindical queda legalmente asegurada en función de la representación concreta a nivel de la empresa o centro de trabajo.

Otra vertiente del problema sería la derivada de la interpretación conjunta de los arts. 14 y 28.1 CE. Aquí, el Tribunal afirma que la regla de la preferencia no implica, de por sí, un tratamiento jurídico desigual entre los sindicatos, que suponga una desproporción irrazonable entre la diferencia de trato adoptada entre aquellos y la finalidad perseguida por la regla legal que la establece; antes bien, reconoce una prelación que es concorde con la diferencia sustancial de implantación, de representatividad, y de ejercicio efectivo de funciones que en nuestro sistema de relaciones laborales existe entre los sindicatos más representativos, y aquellos otros que por no serlo cumplen generalmente una función marginal en la defensa y representación de los intereses de los trabajadores. Ha de excluirse, por ello, que la preferencia que el precepto establece incurra en violación de los arts. 14 y $28.1 \mathrm{CE}$.

\section{II.8. El Sistema ELECTORAL CANARIO (STC 225/1998, DE 25 DE NOVIEMBRE)}

En este pleito impugna el Defensor del Pueblo una disposición transitoria del Estatuto de Canarias en la que se establecían barreras electorales, mediante las cuales solo serían tenidas en cuenta en el reparto de escaños las listas que hubieran obtenido el mayor número de votos de su respectiva circunscripción, o el 6 por 100 de los votos válidos en la Comunidad Autónoma, o el 30 por 100 en cada una de las islas individualmente consideradas. Asimismo se defería a una futura ley del Parlamento canario, aprobada por dos tercios de miembros, la regulación definitiva de la materia. De nuevo aquí nuestro Ombudsman cosecharía una derrota, puesto que el recurso fue desestimado.

Su argumentación se centraba en dos tipos de razonamientos. Por un lado los que tenían que ver con la adecuación del precepto al sistema de fuentes del Derecho. Empieza aquí el Tribunal por decir que el grado de acierto del legislador acerca de la naturaleza temporal o definitiva de la disposición legal impugnada, y su calificación como norma de Derecho transitorio, no es per se elemento condicionante de su constitucionalidad, ni supone en su sola consideración individual una quiebra del principio de 
seguridad jurídica reconocido en el art. 9.3 CE. Además, el precepto estatutario que se recurre es perfectamente claro, y no ofrece especiales dificultades de comprensión, y entendimiento, que puedan inducir a error o confusión. Por otra parte, nos recuerda el TC que las normas estatutarias que regulen materias que queden fuera del ámbito delimitado por la reserva material del Estatuto, pese a que tampoco pueden ser reformadas por procedimientos distintos a los propios de la reforma estatutaria, sí pueden atribuir, en todo o en parte, la determinación definitiva de su contenido al legislador autonómico, que es lo que sucede con la disposición transitoria impugnada. Por más que el legislador estatutario establezca una regulación provisional, lo que hace es deferir al legislador autonómico el contenido definitivo de la regulación, lo que no comporta abrir el Estatuto a un inconstitucional proceso de reforma, sino efectuar una atribución constitucionalmente posible. En último lugar, se afirma que ningún reparo puede existir para que el Estatuto de Autonomía de Canarias pueda, en tanto que "norma institucional básica" (art. 147.1 CE) y, por tanto, norma sobre la producción del derecho propio de la Comunidad Autónoma, imponer una mayoría en orden al ejercicio de la competencia legislativa autonómica sobre la materia.

En cuanto a los aspectos sustantivos del recurso (posible lesión de los arts. 14, 23.2 y $152.1 \mathrm{CE}$ ) el Tribunal dice, en primer término, que no existen dudas sobre la utilización del último de los artículos citados — que dispone que la Asamblea legislativa de la Comunidad Autónoma establecida por el procedimiento del art. $151 \mathrm{CE}$ debe ser elegida "con arreglo a un sistema de representación proporcional» - como canon de constitucionalidad para el enjuiciamiento del precepto estatutario impugnado, conclusión que discute el Abogado del Estado y, en su voto particular, el magistrado Cruz Villalón, para quienes el Estatuto de Canarias, al no haber sido aprobado por la vía del art. $151 \mathrm{CE}$, no está vinculado por el art. 152.1 CE, y, en concreto, por el mandato de establecer un sistema de representación proporcional para su Asamblea Legislativa.

En un análisis más de fondo, el TC concluye que la valoración conjunta del sistema de cláusulas limitativas en el acceso a los escaños no permite afirmar que sea contrario a la proporcionalidad exigida por el art. 152.1 CE. Tampoco se ha acreditado ante este Tribunal que los nuevos porcentajes establecidos hagan perder, por sí solos, al sistema electoral canario su carácter proporcional y, por lo tanto, su capacidad para reflejar las principales opciones políticas existentes en aquella Comunidad Autónoma. No puede estimarse que en virtud de la disposición transitoria tantas veces citada el sistema electoral canario desconozca el criterio, siempre tendencial, de la proporcionalidad con infracción del art. 152.1 CE. 


\section{II.9. LOS LÍMITES DE LA LEY DE PReSUPUeSTOS CANARIA (STC 274/2000,DE 15 DE NOVIEMBRE)}

En la sentencia que se cita en el encabezamiento se revuelve un recurso de inconstitucionalidad del Defensor del Pueblo, basado en la jurisprudencia, muy conocida, sobre los límites de la ley de presupuestos ${ }^{4}$, contra determinados preceptos, dedicados a la regulación del funcionariado, de una ley de este tipo de la Comunidad Autónoma Canaria que, a juicio de aquél, los traspasaban claramente.

En su decisión unánime, el TC, apoyándose en lo que ya había dicho muchas veces, da una de cal y otra de arena, declarando inconstitucionales algunas de las disposiciones de la ley, porque en ellas la misma no se adecua a la función constitucional que le es propia, al incluir normas que no guardan relación directa con el programa de ingresos y gastos, o con los criterios de política económica en que se sustentan, o que no son un complemento necesario para la mayor inteligencia y para la mejor y más eficaz ejecución del Presupuesto (SSTC 174/1998, de 23 de julio y 130/ 1999, de 1 de julio); y constitucionales otras, puesto que se encuentran directamente vinculadas con la política económica del Gobierno de Canarias, siendo su inserción en la ley de presupuestos necesaria para la mejor inteligencia y ejecución de la misma.

Es de resaltar también que, con cierta lógica, las instituciones canarias argumentan que poco tienen que ver las funciones del Defensor del Pueblo con los problemas planteados, pero el Tribunal, siguiendo su doctrina ya consolidada (FJ 2), reafirma que la legitimación de aquél lo es para interponer recurso de inconstitucionalidad por cualquier motivo, y no sólo por los relacionados con derechos fundamentales (por todas, STC 150/1990, de 4 de octubre).

\section{II.10. LAS IMPUGNACIONES DE LAS LEYES ORGÁNICAS DE TRATAMIENTO AUTOMATIZADO Y PROTECCIÓN DE DATOS PERSONALES (SSTC 290 Y 292/2000, DE 30 DE NOVIEMBRE)}

Contra lo que pudiera parecer, dado el enunciado del encabezamiento, en este apartado nos vamos a ocupar con detalle solamente de la segunda de las sentencias citadas, puesto la primera se limita a declarar la pérdida sobrevenida del objeto de los recursos interpuestos por los Diputados del Grupo Parlamentario Popular, y por el Defensor del Pueblo, contra determinados artículos de la derogada Ley Orgánica 5/1992, de 29 de octubre, de Regulación

4 En relación con los inicios de la misma permítaseme remitir a I. TORRES MURO, "Las peculiaridades de la ley de presupuestos en la reciente jurisprudencia constitucional”; Revista Española de Derecho Constitucional n. ${ }^{\circ} 49$ (1997). 
del Tratamiento Automatizado de los Datos de Carácter Personal, y a resolver temas de distribución de competencias que estos no habían impugnado.

En la segunda sentencia, sin embargo, lo que se combaten son determinados contenidos de la Ley Orgánica 15/1999, de 15 de diciembre, de protección de datos de carácter personal, sucesora de aquella.

Hay que señalar que aquí el Defensor del Pueblo obtiene una clara victoria, pues el Tribunal Constitucional llegó a sostener, según se le pedía, que, primero, el art. 21.1 de la Ley es inconstitucional porque no ha fijado por sí mismo, como le impone la Constitución (art. 53.1 CE), los límites al derecho a consentir la cesión de datos personales entre Administraciones Públicas para fines distintos a los que motivaron originariamente su recogida, sino que se ha limitado a identificar la norma que puede hacerlo en su lugar. Norma que bien puede ser reglamentaria, ya que con arreglo al precepto será una norma de superior rango, y con mayor razón para el caso de que la modificación lo sea por una norma de similar rango, a la que crea el fichero, la que pueda autorizar esa cesión inconsentida de datos personales, lo que resulta ser, desde luego, contrario a la Constitución.

En el caso de la redacción de los arts. 24.1 y 2 de la Ley, el TC encuentra que el uso de la expresión "funciones de control y verificación" abre un espacio de incertidumbre muy amplio, porque habilita a la Administración para que restrinja derechos fundamentales, y se renuncia a fijar los límites por ley. Un grado de incertidumbre aún mayor encierra el empleo de la expresión «interés público" como fundamento de la imposición de límites a los derechos fundamentales del art. 18.1 y 4 CE.

Las mismas tachas merecen las restricciones relativas a la persecución de infracciones administrativas (art. 24.1) y la garantía de intereses de terceros más dignos de protección (art. 24.2). Respecto a la primera, el Tribunal razona que la posibilidad de que la Administración pueda sustraer al interesado información relativa al fichero, y sus datos, invocando los perjuicios que semejante información pueda acarrear a la persecución de una infracción administrativa, supone una grave restricción de los derechos a la intimidad, y a la protección de datos, carente de todo fundamento constitucional. En cuanto a la segunda, la falta evidente de certeza y previsibilidad del límite que el art. 24.2 de la Ley impone al derecho fundamental a la protección de los datos personales (art. 18.4 CE) (denegación de acceso, rectificación y cancelación si "ponderados los intereses en presencia, resultase que los derechos que dichos preceptos conceden al afectado hubieran de ceder ante...intereses de terceros más dignos de protección") y la circunstancia de que, además, se trate de un límite cuya fijación, y aplicación, no viene precisada por dicha Ley, sino que se abandona a la entera discreción de la Administración Pública responsable del fichero en cuestión, aboca a concluir que han resultado vulnerados los arts. 18.4 y $53.1 \mathrm{CE}$. 


\section{II.11. LA REGULACIÓN DE LA "RETENCIÓN" DE LOS SOLICITANTES DE ASILO} (STC 53/2002, DE 27 DE FEBRERO)

La impugnación del Defensor ${ }^{5}$, resuelta por la sentencia citada, se centra en el régimen de restricciones a la libertad establecidas por el art. 5.7.3 de la Ley de Derecho de Asilo, que, contra lo que aquel argumenta, el TC considera como ciertas, y claramente limitadas: tanto en relación con los sujetos afectados (únicamente los extranjeros peticionarios de asilo cuya solicitud aún no ha sido admitida a trámite) como en el tiempo (un máximo de cuatro días, y dos días más si, inadmitida la solicitud, se paraliza la expulsión del extranjero por medio de una petición de reexamen), en el espacio (no impide el retorno del extranjero a su lugar de procedencia, o su entrada en otro Estado) y en el modo de la restricción (ausencia de régimen penitenciario o disciplinario). Y es también, una limitación a la libertad plenamente controlada: ora en forma administrativa (con posible intervención de un representante de ACNUR) ora en forma judicial.

Todo ello lleva al Tribunal a concluir que el fondo de la norma no es inconstitucional. Pero el Defensor impugnaba también la forma, sosteniendo que hacía falta regular el tema con una Ley Orgánica. Tampoco aquí tienen éxito sus pretensiones porque el TC concluye que la regulación del artículo citado no constituye un desarrollo frontal del derecho a la libertad personal, ni las restricciones que establece suponen una limitación esencial de la misma, que son los supuestos en que — de acuerdo con el art. 81.1 CE- se exige la reserva de ley orgánica.

Tiene interés lo que dicen los dos votos particulares que se formulan. En el primero, los magistrados Vives, Jiménez, y Delgado, afirman que en realidad nos hallamos ante una restricción de la libertad de acceso al territorio nacional aplicable a los solicitantes de asilo en España que no constituye contenido propio (ni posible) de una Ley Orgánica. No hay, para ellos, ninguna privación de libertad. En el segundo, el magistrado Cachón sostiene que para declarar la constitucionalidad del precepto había que integrarlo con las previsiones del art. 21.2 de la misma ley (suspensión de las medidas cuando se interponga recurso contencioso-administrativo) y hacer una interpretación conforme en la que se incluyese la referencia a la normativa reglamentaria que lo desarrolla (art. 39.2 del RD 203/1995, de 10 de febrero; autorización de la entrada y permanencia del solicitante en el territorio hasta que los jueces resuelvan sobre la suspensión).

5 Una explicación más a fondo de la misma, realizada por un asesor de la institución en J. M. FERNÁNDEZ MATEOS Apuntes sobre extranjería desde el Defensor del Pueblo, en P. BIGLINO CAMPOS (coord.) Ciudadania y extranjeria: Derecho Nacional y Derecho Comparado, McGraw Hill, Madrid, 1998, págs. 113 y ss. 


\section{II.12. LA ASISTENCIA JURÍDICA GRATUITA A LOS EXTRANJEROS (STC 95/2003, DE 22 DE MAYO)}

Un caso de éxito rotundo de un recurso de inconstitucionalidad del Defensor del Pueblo es el que se da en la sentencia citada en el encabezamiento. Allí el Tribunal Constitucional dictamina que cerrar al extranjero, que no dispone de recursos suficientes, la posibilidad de gozar del beneficio de justicia gratuita para pleitear en nuestros tribunales, supone una vulneración del derecho a la tutela judicial efectiva, consagrado en el art. 24.1 CE, del que son titulares también los extranjeros no residentes legalmente en España, vulneración que, al resultar de la propia norma legal [inciso "que residan legalmente en España" del apartado a) del art. 2 de la Ley de asistencia jurídica gratuita], hace que ésta se encuentre afectada de un vicio de inconstitucionalidad. Para el TC, la expresión de la ley "que residan" habrá de entenderse referida a la situación puramente fáctica de los que se hallen en territorio español. Por otra parte, los extranjeros que se encuentren en España, y reúnan las condiciones requeridas legalmente para ello, podrán acceder a la asistencia jurídica gratuita en relación con cualquier tipo de proceso a efectos del cual gocen de la precisa legitimación.

Tres magistrados formularon voto particular. Conde sostuvo que el derecho a la justicia gratuita (art. $119 \mathrm{CE}$ ) no está comprendido en el derecho a la tutela judicial efectiva (art. 24.1 CE). De lo que deduce que es discutible que por exigencia constitucional directa el legislador deba reconocer a todos los extranjeros, al margen de la legalidad o ilegalidad de su residencia en España, dicho derecho. García-Calvo argumenta que una vez que el legislador reformó la Ley de asistencia jurídica gratuita y admitió, de modo generalizado, y sin reserva alguna relacionada con la residencia, la asistencia jurídica gratuita en los procesos contencioso-administrativos en los que estaba en juego la entrada o expulsión de los extranjeros, no resultaba obligado ex Constitutione reconocer este derecho a todos los extranjeros en todos los procesos. Y, por su parte, Rodríguez-Zapata, argumenta que la igualdad en la atribución, o titularidad, del derecho a la tutela judicial efectiva no implica excluir una regulación legislativa distinta del beneficio de justicia gratuita, siempre que se ajuste a cánones de proporcionalidad y razonabilidad.

\section{II.13. SOBRE LA INTEGRACIÓN DE PROFESORES DE IKASTOLAS EN LA FUNCIÓN PÚBLICA VASCA (STC 31/2006, DE 1 DE FEBRERO)}

El intento de integrar en la función pública vasca, aún careciendo de la específica titulación para el acceso, y mediante pruebas selectivas restringidas que, con carácter excepcional, podían ser convocadas por la Administración educativa, a los docentes que tuviesen la condición de personal laboral fijo (art. 10 de la Ley del País Vasco 16/1997 de 7 de noviembre, que introduce un 
nuevo apartado 3 en la disposición adicional segunda de la Ley 6/1989, de 6 de julio, de la función pública vasca) fue combatido con tres recursos de inconstitucionalidad por el Defensor del Pueblo, más de cincuenta Senadores del Grupo Parlamentario Socialista, y el Presidente del Gobierno.

La argumentación de los recurrentes es similar, y a ella contesta el TC estimando los recursos porque, en primer lugar, con independencia de que la normativa autonómica pudiera vulnerar el derecho de acceso a las funciones públicas, en todo caso no respeta la normativa básica, ya que aquélla ha sido dictada una vez que el plazo temporal de cinco años previsto en ésta para realizar este tipo de convocatorias había caducado. El simple hecho de que se dicte la norma que prevé la convocatoria restringida de acceso a la función pública más allá del plazo conferido en la normativa básica determina su inconstitucionalidad, sin que sea posible realizar, una lectura conforme a la Constitución del precepto impugnado.

En segundo lugar, es claro que no estamos ante una mera medida de promoción del personal funcionario, sino de la conversión de personal laboral contratado por personas y entidades jurídico-privadas, y asumido después a través de una relación laboral por la Administración autonómica, que pretende integrarse por esta vía en la función pública docente, sin contar con la titulación exigida por la normativa estatal básica, normativa que, además, exige, incluso en los supuestos de acceso restringido a la función pública docente, que los candidatos cuenten con la titulación exigida para los cuerpos en los que se integran, salvo en supuestos tasados. Se desconocen así los principios de mérito y capacidad previstos para el acceso a la función pública, de modo que se menoscaba la capacidad como requisito absoluto para el desempeño de cada puesto de trabajo concreto, y se niega el mérito como elemento relativo de comparación y preferencia para el acceso o nombramiento. Concluye el Tribunal diciendo que si no se hubiera afirmado que el precepto impugnado es inconstitucional por vulnerar la normativa estatal básica en materia de función pública (art. 149.1.18 CE), se hubiera alcanzado idéntica conclusión en lo que atañe a los artículos 23.2 y 103.3 CE.

\section{II.14. Censo y presupuestos del Estado (STC 45/2007, De 1 de marzo)}

Un caso en el que el Defensor actuó en defensa de los intereses de determinados ayuntamientos, los que habían visto crecer su población, es el que resolvió la última sentencia en un recurso de inconstitucionalidad presentado por el mismo.

El objeto era la impugnación del inciso final — "la contenida en el censo de 1991»— del primer párrafo del art. 72 de la Ley 49/1998, de 30 de diciembre, de Presupuestos generales del Estado para 1999. Allí se consideraba, a los efectos de la liquidación definitiva de la participación en tributos del Estado correspondiente al ejercicio 1997, el censo o padrón renovado, oficialmente aprobado por el Gobierno, y vigente en 1 de enero de 1997, que era del de 
1991, y no el de 1996, que no fue declarado oficial hasta el Real Decreto de 31 de octubre de 1997.

El Defensor del Pueblo sostiene que se ha vulnerado el art. 14 CE (principio de igualdad) y el 9.3 CE (proscripción de la arbitrariedad). El Tribunal contesta contundentemente, desestimando los dos motivos de recurso. Respecto al primero, señala su falta de sustantividad propia, entre otras cosas porque los entes públicos no pueden ser considerados titulares del derecho proclamado en el art. $14 \mathrm{CE}$.

En cuanto al segundo, nos recuerda que el control de constitucionalidad de las leyes debe ejercerse por este Tribunal de forma que no se impongan restricciones indebidas al Poder Legislativo, y se respeten sus opciones políticas. Concluye un prolijo repaso del problema señalando que no puede calificarse de arbitraria la utilización de los datos de población reflejados en la renovación quinquenal del padrón municipal llevada a cabo en 1991 para proceder a la liquidación definitiva de la participación de los municipios en los tributos del Estado correspondiente al ejercicio presupuestario de 1997. La norma impugnada no se muestra desprovista de fundamento, aunque pueda legítimamente discreparse de la concreta solución, y posee una finalidad razonable, dado que es una especificación de la Ley de las haciendas locales que llama a la Ley aprobatoria de los Presupuestos generales del Estado para completar su programa normativo en punto a la liquidación de la participación de los municipios en los tributos del Estado.

\section{II.15. AlgunOS RECURSOS PENDIENTES MUy Significativos. Estatuto CATALÁN y Ley del Sindic de GReuges}

Los acontecimientos derivados del proceso que concluyó, en 2006, con la aprobación del nuevo Estatuto de Cataluña, y algunos de los desarrollos realizados de esta norma, han llevado al Defensor del Pueblo a interponer los correspondientes recursos de inconstitucionalidad, tanto frente al texto de aquel, como contra la ley que desarrolla, tras el Estatuto, su institución hermana, el Sindic de Greuges.

En el bien entendido de que el Tribunal Constitucional no se ha pronunciado todavía sobre los mismos, creemos que es necesario dar cuenta, con la necesaria concisión, de las razones de estos recursos del Defensor.

En cuanto a la primera de la impugnaciones - Estatuto de Cataluña- el Defensor del Pueblo, cuya legitimación para presentar un recurso de inconstitucionalidad fuera de su ámbito natural de defensa de los derechos fundamentales se discute, una vez más, por las instituciones de la Generalidad en sus escritos contestando a las argumentaciones de aquél, se ocupa de un abanico muy amplio de problemas. Empieza por alzarse contra los preceptos referidos al origen de los poderes de la Generalidad y al fundamento del autogobierno de Cataluña, en relación con la consideración de Cataluña como nación. Impugna el inciso del art. 2.4 EAC con arreglo al cual «los poderes de 
la Generalitat emanan del pueblo de Cataluña", y el inciso del art. 5 EAC en el que se dispone que "el autogobierno de Cataluña se fundamenta también en los derechos históricos del pueblo catalán"; ambos en relación con la afirmación del preámbulo del Estatuto de que «la Constitución española...reconoce la realidad nacional de Cataluña como nacionalidad".

En cuanto a los derechos, deberes, y principios rectores, reconocidos en el Título I del Estatuto, para el Defensor del Pueblo este ha desbordado sus límites constitucionales, infringiendo el art. $147 \mathrm{CE}$, al tiempo que se produce una restricción ilegítima de la potestad legislativa del Estado, en contradicción con el art. 66.2 CE.

Argumenta asimismo el Defensor que el régimen lingüístico estatutario es inconstitucional por la imposición a los ciudadanos de Cataluña del deber de conocimiento del catalán, por el carácter preferente atribuido al catalán en las instituciones y entidades públicas de Cataluña, por la imposición del deber de mantener, también en catalán, todas las comunicaciones, orales y escritas, con los consumidores y usuarios, y por imponer a los órganos constitucionales estatales la obligación de tramitar los escritos presentados en catalán.

Un punto especialmente importante para el Defensor del Pueblo es, con toda lógica, la regulación del Sindic de Greuges. En su opinión, la normativa recurrida pretende expulsarle de los ámbitos competenciales autonómico y local de Cataluña, pues sólo le cabría efectuar la supervisión de la Administración estatal presente en dicho territorio, parcela en la que, además, habría de colaborar en el ejercicio de sus funciones con el Sindíc de Greuges.

No paran aquí sin embargo, las impugnaciones del Defensor. También alega respecto a la constitucionalidad de muchos de los preceptos del Estatuto relativos al poder judicial y a la administración de justicia, de los que se ocupan de la composición de ciertos órganos estatales, de las disposiciones adicionales sobre la cesión de impuestos a la Generalitat, de los relativos al sistema de asunción de competencias por la Generalitat de Cataluña, y, por fin, de los reguladores de las relaciones de la Generalitat de Cataluña con el Estado y con la Unión Europea.

Consecuencia de este recurso es el presentado contra la Ley catalana 24/2009, de 23 de diciembre, del Sindíc de Greuges, en el que, por un lado, el Defensor del Pueblo combate la interpretación de dicha ley en el sentido de excluirle de la supervisión de la Administración local catalana, y el intento de imponerle un determinado modelo de relaciones de colaboración.

Por otro, le parece inconstitucional la atribución que se hace al Sindic de Greuges de la condición de Autoridad Catalana para la Prevención de la Tortura y de otros Tratos o Penas Crueles, Inhumanos o degradantes, cuando dichas competencias son exclusivas del Estado. Las Cortes Generales (Ley Orgánica $1 / 2009$, de 3 de noviembre) han decidido que hay un Mecanismo de Prevención (el Defensor del Pueblo) y no varios. La ley catalana desconocería la competencia exclusiva del Estado en materia de relaciones internacionales, establecida en el art. 149,1 $3^{\text {a }}$ CE. El Parlamento de Cataluña, con dicha designación del Sindic de Greuges, ha pretendido, para el Defensor, invadir la 
reserva del Estado en sus relaciones con la ONU; ha pretendido atribuirse obligaciones inmediatas y actuales ante el Subcomité de Prevención de la Tortura de Naciones Unidas que, además, pueden generar responsabilidad del Estado en caso de incumplimiento; y, en fin, ha pretendido perturbar o condicionar la reserva del Estado en materias internacionales.

\section{LOS RECURSOS DE AMPARO DEL DEFENSOR DEL PUEBLO}

Las sentencias producto de recursos de amparo interpuestos por el Defensor del Pueblo son muchas menos que las que hemos visto que son consecuencia de recursos de inconstitucionalidad del mismo órgano, probablemente porque esta legitimación no haya acabado de calar en un contexto en el que la amplitud de la de los sujetos en presencia es bastante significativa. Aún así, nos encontramos hasta ahora con tres decisiones (dos sentencias y un auto) de las que pasamos a dar cuenta.

\section{III.1. IMPUGNACIÓN DE ELECCIONES SINDICALES (STC 178/1987, DE 11 DE NOVIEMBRE)}

En el primero de los casos, el Defensor del Pueblo impugna las sentencias de una Magistratura de Trabajo que sostenían que para que el órgano judicial entrara a conocer del fondo de la pretensión ejercitada ante el mismo, respecto de las elecciones sindicales, debía el actor, de acuerdo con ciertas normas legales que interpretaba en ese sentido, haber formulado protesta o reclamación ante la mesa electoral, siendo este un presupuesto previo e ineludible.

Al Tribunal le parece que se han traspasado los límites en la función de aplicación e interpretación del Derecho, propia de los órganos judiciales, ya que se ha aplicado con rigorismo formal un presupuesto impeditivo de la solución de fondo, fin último de la función jurisdiccional, es decir, de la tutela efectiva de los derechos. Constata, por tanto, la existencia de una vulneración del derecho a la tutela judicial efectiva, reconocido en el art. 24.1 CE, en su vertiente de derecho a obtener una resolución sobre el fondo del litigio.

\section{III.2. IGUALDAD EN PRESTACIONES DEL SUBSIDIO PREVIO A LA JUBILACIÓN} (STC 209/1987, DE 22 DE DICIEMBRE)

En favor de un ciudadano, interpuso en este caso recurso de amparo el Defensor del Pueblo contra la denegación a un trabajador por cuenta ajena, afiliado al Régimen General de la Seguridad Social, del subsidio de desempleo del que pueden beneficiarse los trabajadores mayores de cincuenta y cinco 
años, por todo el período que resta hasta la fecha de su jubilación. Lo que se planteó ante el TC era si dicha denegación era contraria al principio de igualdad ante la Ley. La misma se basaba en una norma reglamentaria que exigía que el trabajador reuniera, para gozar de dicha prestación, todos los requisitos para jubilarse como trabajador por cuenta ajena en cualquiera de los Regímenes de la Seguridad Social en los que se le reconozca el derecho al subsidio por desempleo. Por ello, le excluía del subsidio asistencial al que hemos hecho referencia, al haber sido durante muchos años trabajador autónomo, afiliado al correspondiente Régimen especial.

Para el Tribunal Constitucional, el Tribunal Central del Trabajo debió inaplicar esa norma reglamentaria —interpretando la ley del modo más conforme a la plena efectividad de la igualdad- $y$, por tanto, dio apoyo a una diferenciación carente de todo fundamento legal y, por lo mismo, discriminatoria. La consecuencia es el otorgamiento del amparo, reconociendo el derecho del recurrente a que no se aplique en su contra la condición establecida en el inciso final del art. 7.3 del Real Decreto 625/1985.

\section{III.3. UN DESISTIMIENTO PORQUE LOS REPRESENTADOS EJERCEN POR SÍ SU DERECHO (ATC 94/1984, DE 15 DE FEBRERO)}

En el caso correspondiente el Defensor del Pueblo ejercitó la pretensión de indefensión, que acoge el art. 24.1 CE, con carácter meramente subsidiario, respecto a las personas que pudieran resultar particularmente interesadas por la sentencias impugnadas. Al serles admitidos a estas los recursos de amparo correspondientes, con el mismo contenido material que el del Defensor, resulta evidente que la legitimación de dicha institución, meramente concurrente y ejercitada ad cautelam, decayó, de lo que se deduce, tras confirmar el Ombudsman su voluntad de desistir, el desistimiento del proceso, y el archivo de las actuaciones.

\section{OTROS PLEITOS EN LOS QUE HA ESTADO INVOLUCRADA LA INSTITUCIÓN}

Además de todos estos procesos en los que el Defensor del Pueblo aparece como recurrente, ha habido otros, no demasiados, en los que se han ventilado temas relativos al mismo, en los que éste tenía un evidente interés. Se trata de los que concluyeron con las SSTC 142/1988, de 12 de julio, 157/1988, de 15 de septiembre, y 162/1996, de 17 de octubre, y todos tienen que ver con las instituciones afines de las Comunidades Autónomas.

En la primera de ellas se resuelve un recurso de inconstitucionalidad del Presidente del Gobierno contra la Ley aragonesa 4/1985, reguladora del Justicia de Aragón, haciendo primero una interpretación conforme, en el sentido 
de que la facultad de este órgano, de dirigirse a los de cualquier Administración presente en el territorio de Aragón, y por tanto también a los del Estado, debe entenderse que excluye toda idea de subordinación o imposición de deberes, de modo que se impide cualquier extralimitación del ámbito propio que para la actuación del Justicia establece el Estatuto de Autonomía. Por otra parte, el otorgamiento a éste de la posibilidad de dirigirse a las autoridades competentes, que tengan acciones ante los Tribunales, a los efectos de solicitarles su actuación para defender el Estatuto, no tiene el alcance de norma procesal reservada a la Ley Orgánica del Poder Judicial y no incurre, por tanto, en el vicio de incompetencia alegado.

Un nuevo ejemplo de interpretación conforme es la que se hace de la norma sobre la supervisión de los entes locales, que hay que entender que sólo podrá ejercerse en materias en las que el Estatuto de Autonomía atribuya competencias a la Comunidad Autónoma de Aragón, y respecto de las que éste haya, además, transferido o delegado en los entes locales.

Por fin, tres normas son recurridas por afectar, a juicio del recurrente, a las competencias reconocidas a la legislación estatal. El Tribunal afirma que así es en el caso de la referente a la correspondencia de los presos, que invade la reserva al Estado de la materia de los derechos de los presos y detenidos, pero lo niega en el de las declaraciones de la ley sobre la responsabilidad penal en la que pudieran incurrir quienes obstruyeran las actividades del Justicia, porque no se trata de legislación penal exclusiva del Estado, y en el de la posibilidad de dar traslado al Fiscal de hechos susceptibles de constituir delito o falta, que contempla un deber del Justicia que no supone por sí mismo normativa procesal alguna.

En la STC 157/1988, de 15 de septiembre, es el Parlamento de Cataluña el que recurre contra el inciso "así como de las Administraciones de los Entes locales, cuando actúen en ejercicio de competencias delegadas por aquélla" (la Comunidad Autónoma), contenido en el art. 2, párrafo 1, de la Ley 36/1985, de 6 de noviembre, que regula las relaciones entre el Defensor del Pueblo y las figuras similares de las Comunidades Autónomas. El Tribunal niega la inconstitucionalidad porque el precepto impugnado amplía la capacidad de actuación de los Comisionados parlamentarios autonómicos, y no contradice el Estatuto de Cataluña, dado que no regula competencia alguna de las figuras autonómicas análogas al Defensor del Pueblo, y porque delimitar supuestos de cooperación entre éste y los Comisionados parlamentarios no puede afectar negativamente al deber de los poderes públicos de Cataluña de promover las condiciones y remover los obstáculos a la libertad e igualdad de ciudadanos y grupos sociales que contempla el art. 8 de su Estatuto.

Por fin, la STC 162/1996, de 17 de octubre, es producto de un recurso de inconstitucionalidad del Presidente del Gobierno frente a la ley valenciana 11/1988, de 26 de diciembre, del Síndico de Agravios, que pretendía establecer en uno de sus preceptos una norma penal que configuraba un tipo (correspondiente al delito de desobediencia), con la excusa de que lo que se hacía era desarrollar lo previsto en la legislación sobre el Defensor del Pueblo 
(art. 24.2 de la LODP), y sobre las relaciones entre éste y figuras afines, siendo así que se incorporaban ciertas modificaciones de redacción mediante las que se establecía un delito diferente. El Tribunal reacciona con contundencia, y afirma que eso es "legislación penal" (art. 149.1.6 CE) reservada a la competencia exclusiva del Estado, y vedada al legislador autonómico.

\section{UN RESULTADO POBRE, PERO CON ALGUNOS MOMENTOS DE GLORIA}

Si nuestro artículo se quedara aquí constituiría solamente una crónica jurisprudencial, más o menos aseada, relativa a las decisiones del TC en las que, de una u otra forma, ha estado involucrado el Defensor del Pueblo. Pretendemos hacer algo más, y añadir a la exposición un poco de reflexión, también porque creemos que el recorrido que acabamos de realizar por sentencias y autos nos permite ahora elevar el tono del discurso, e intentar hacer unas reflexiones generales sobre el sentido, y los resultados, de la legitimación de nuestro Ombudsman ante el Tribunal Constitucional ${ }^{6}$.

Lo primero que llama la atención es que el Defensor del Pueblo ha hecho uso de la misma relativamente pocas veces. Esto es más claro aún en el caso del recurso de amparo, en donde se explica, sin ningún problema, por una realidad en la que las reglas sobre legitimación y asistencia jurídica gratuita de los diferentes sujetos, y la interpretación que de las mismas ha hecho el TC, dotándolos de muchas facilidades para acceder a este tipo de procesos, para lo que basta tener un interés legítimo, han hecho que no resulte necesario acudir al Defensor para que recurra en nuestro nombre. Por ello, se ha recurrido muy pocas veces, en un intento de dotar de un mayor peso a la impugnación, o de que aumenten las posibilidades de éxito, pero los resultados, como hemos visto, han sido bastante magros: escasamente dos sentencias con algo de importancia. Se ha hablado, con razón, de "actuación restrictiva" puesto que se ha hecho "uso de esta atribución sólo si hay dudas sobre la legitimación activa de otros sujetos ${ }^{7}$. Parece claro que las previsiones de la ley en este terreno han quedado prácticamente vírgenes.

Tampoco en el caso del recurso de inconstitucionalidad puede decirse que haya sido muy frecuente esta actividad del Defensor del Pueblo, a juzgar por los resultados obtenidos, que, a día de hoy, se limitan a poco más de una docena de sentencias que, comparadas con las que ha dictado, hasta

6 Para los debates respecto a la legitimación ante los Tribunales del Defensor del Pueblo, en la Constitución y en las leyes de desarrollo, cabe remitir a M. J. CORCHETE MARÍN El Defensor del Pueblo y la protección de los derechos, Universidad de Salamanca, Salamanca, 2001, págs. 28 y ss. También contiene mucha información al respecto el comentario de C. LUNA ABELLA al art. 29, recogido en A. ROVIRA VIÑAS (dir.) Comentarios a la Ley Orgánica del Defensor del Pueblo, Aranzadi, Cizur Menor, 2002, págs. 713 y ss.

7 Juan Luis Pérez Francesch "El Defensor del Pueblo en España: balance de veinticinco años de experiencia constitucional", Revista de Estudios Políticos (n. e.) n. ${ }^{\circ} 128$ (2005), pág. 81. 
ahora, el Tribunal Constitucional, en estos terrenos, no son, desde luego, muchas.

No cabe duda, sin embargo, de que esta legitimación tiene más sustancia, y es más polémica, que la del recurso de amparo. En principio, parece diseñada para que puedan acceder al control de constitucionalidad de las leyes sectores excluidos por una regulación muy restrictiva, como la contenida en los arts. 162 CE y 32 LOTC, que no permite, desde luego, la acción popular. El Defensor se configura así como una alternativa para quienes no son ni el Presidente del Gobierno, ni cincuenta Diputados o cincuenta Senadores, ni órganos colegiados ejecutivos o Asambleas legislativas de las Comunidades Autónomas.

Podría incluso representar el papel, previsto por Hans Kelsen en su modelo ideal de jurisdicción constitucional, de garante o defensor de la Constitución que a semejanza del ministerio público en el proceso penal, debería instar de oficio en el procedimiento de control de constitucionalidad para aquellos actos que estimara irregulares". Ha de tenerse en cuenta, en todo caso, que, como sigue diciendo el autor austriaco, "va de suyo que el titular de semejante función habría de estar revestido de todas las garantías imaginables de independencia tanto frente al Gobierno como frente al Parlamento" ${ }^{8}$.

Pero no creemos que nuestro Defensor del Pueblo haya llegado a niveles tan trascendentes. Más bien ha intentado, con mayor o menor fortuna, suplir algunas de las carencias del sistema, convirtiéndose en algunos casos en la vOz de los sin vOz (extranjeros, sindicatos minoritarios, usuarios de sistemas informáticos, etc).

Lo primero que conviene revisar, a la luz del repaso que hemos hecho en la primera parte de este trabajo, es cuál ha sido el porcentaje de éxito de estos intentos. En el caso de los recursos de amparo ya sabemos que de un cien por cien. Las dos sentencias dictadas otorgan el mismo. Habría que conocer lo que ha pasado con los procesos que no han llegado a sentencia, pero que todas las decisiones finales tomadas lo hayan sido a favor del recurrente es un dato importante.

Los resultados en el caso de los recursos de inconstitucionalidad presentan otra cara. Es prácticamente igual el número de los que se estiman que el de los que se desestiman, lo cual no deja de ser un nivel de éxito bastante significativo, dadas las dificultades para arrancar al TC una declaración de inconstitucionalidad. Hay que revisar, sin embargo, la imagen de que la mayoría de las sentencias recaídas en estos procesos instados por el Defensor del Pueblo son estimatorias ${ }^{9}$ porque dicho órgano ha sufrido bastantes, y significativos, revolcones en esta actividad.

8 La garantía jurisdiccional de la Constitución (La justicia constitucional) (1928); ahora en H. KELSEN Escritos sobre la democracia y el socialismo, Debate, Madrid, 1988, pág. 147.

9 Que transmite M. PÉREZ-UGENA en «El Defensor del Pueblo en los procesos de tutela constitucional", Revista de la Facultad de Derecho de la Universidad Complutense n. 84 (1995), pág. 357. Este artículo constituye, a pesar del tiempo transcurrido, una buena introducción a muchos de los problemas de la legitimación del Defensor del Pueblo para interponer recursos de inconstitucionalidad y amparo. 
Pero este, en cierto modo pedestre, análisis cuantitativo debe venir acompañado de otro de tipo cualitativo que se pregunte cuál ha sido la influencia, y en qué materias, de los recursos del Defensor. Asimismo, cabe replantearse si la práctica se ha correspondido con alguno de los principios con los que la doctrina, y los mismos ocupantes de la institución, han procurado orientarla.

En primer lugar hay que hacer referencia al problema de la amplitud de la legitimación. Ya sabemos que es un tema recurrente, que aparece siempre que el recurso desborda los límites estrictos de los derechos fundamentales. Joaquín Ruiz-Giménez, el primer ocupante del cargo, al referirse a como se había articulado este asunto, dijo, en su momento que el Defensor había "tenido prioritariamente en cuenta...si en la ley cuya impugnación se pretendía, era de apreciar una presunta violación de un derecho fundamental ${ }^{10}$.

En la doctrina ha habido cierta polémica entre quienes (Valera, Aragón, Espín, Vera) sostienen que el recurso debe interponerse solamente en los casos en los que se infrinjan los derechos subjetivos reconocidos en el Título I de la Constitución, y quienes (Carro Fernández-Valmayor, Carballo Armas) consideran que el Defensor lo es de toda la norma fundamental ${ }^{11}$.

En todo caso, el Tribunal Constitucional ha dicho con rotundidad que "con independencia de la cualidad del Defensor del Pueblo como alto comisionado de las Cortes Generales para la defensa de los derechos comprendidos en el Título I, su legitimación al respecto ha de entenderse en los mismos términos y con la misma amplitud que la del resto de los sujetos contemplados conjuntamente en los arts. 162.1 a) y 32,1 LOTC" (por todas, STC 274/2000, de 15 de noviembre, FJ 2 "in fine").

Lo que ha sucedido en la práctica es que nuestro Ombudsman, aunque normalmente ha procurado defender derechos, tampoco se ha limitado a esa tarea. Es verdad que se ha batido por los derechos de los extranjeros (SSTC 115/1987, de 7 de julio, 53/2002, de 27 de febrero, o 95/2003, de 22 de mayo), por temas relacionados con la libertad sindical (SSTC 20/1985, de 14 de febrero, 26/1985, de 22 de febrero, 72/1985, de 13 de junio, 101/1991, de 13 de mayo, 75/1992, de 14 de mayo, y AATC 636/1985, de 26 de septiembre, y 812/1988, de 21 de junio), o con el derecho a la objeción de conciencia (STC 160/1987, de 27 de octubre), el derecho al sufragio (STC 225/1998, de 25 de noviembre), la libertad informática (STC 292/2000, de 30 de noviembre), o el derecho al acceso en condiciones de igualdad a los cargos públicos (STC 274/2000, de 15 de noviembre, y 31/2006, de 1 de febrero). Pero también lo es que en determinados casos, como en la STC 150/1990, de 4 de octubre, o

10 Op. cit., en nota 3, pág. VII

11 Una exposición más detallada de ambas posturas en I. TORRES MURO La legitimación..., op. cit., en nota 2, págs. 46-47. Las reflexiones de J. M. VERA se encuentran en su edición de textos titulada El Defensor del Pueblo en la Constitución y en los Estatutos de Autonomía, CEPCBOE, Madrid, 2002, concretamente en su estudio preliminar, pág. 48, en donde se habla de "criterio interpretativo finalístico, para la consecución de las funciones que el ordenamiento le confiere». Ver allí también la nota el pie 35. 
la STC 45/2007, de 1 de marzo, la conexión con los derechos fundamentales es más bien tenue.

Preocupante resulta, desde luego, la deriva adoptada en el recurso contra el Estatuto de Cataluña, en donde, si bien es cierto que el Defensor combate interpretaciones en temas de derechos lingüísticos, o derechos en general, y, asimismo, defiende, como es lógico, su posición institucional frente al intento de recortarle drásticamente competencias, también lo es que entra en temas del todo ajenos al mundo de los derechos fundamentales, como el de si Cataluña puede definirse como nación, o los sistemas de relaciones Estado-Comunidad Autónoma, por poner dos ejemplos claros.

Independientemente de que la postura del Tribunal Constitucional, a la que ya hemos hecho referencia, y que parece irreprochable, es meridianamente clara en el sentido de que el Defensor no tiene límites en su legitimación, no estaría de más que el órgano se mantuviera fiel a esas autolimitaciones a las que hacia referencia su primer titular, porque el papel de "Fiscal de la Constitución" en el sentido kelseniano, del que también hemos hablado ya, sinceramente creemos que le viene un poco grande, y es uno que le crearía muchos más problemas que beneficios, aparte de poder convertirlo en un factor de desestabilización, cosa que no juzgamos deseable en una institución que debiera dedicarse preferentemente a la amable composición de conflictos entre la Administración y los administrados.

Lo segundo que en la primera época se tuvo "prioritariamente en cuenta" fue "si no había ejercitado la legitimación....alguna otra de las personas a las que el artículo 162 de la Constitución atribuye esas mismas facultades ${ }^{12}$. Lo cierto es que en pocas ocasiones el Defensor ha recurrido junto a otros órganos legitimados. Se trata del caso de la Ley madrileña del Fondo de Solidaridad Municipal (STC 150/1990, de 4 de octubre, junto con Diputados del Grupo Parlamentario Popular), de la impugnación de la Ley de Regulación del Tratamiento Automatizado de los Datos de Carácter Personal (STC 290/2000, de 30 de noviembre, junto al Consejo Ejecutivo de la Generalidad, el Parlamento de Cataluña y Diputados del Grupo Parlamentario Popular), de la reforma de la función pública vasca (STC 31/2006, de 1 de febrero, junto al Presidente del Gobierno, y Senadores socialistas), y, por supuesto, el caso del Estatuto de Cataluña en el que acompaña a Diputados del Grupo Popular, y a diversos órganos autonómicos, aunque aquí no se han acumulado los recursos, y habrá diversas sentencias.

Como vemos, el Defensor ha sido bastante fiel a las intenciones proclamadas. La mayoría de sus impugnaciones se han producido cuando nadie más hacía uso de sus facultades en ese sentido, y ese uno de sus principales valores, el de romper posibles situaciones de bloqueo en las que los poderes establecidos pretendan tomar una medida inconstitucional, y hayan conseguido que la misma no sea cuestionada por los principales actores políticos.

12 RUIZ-GIMÉNEZ en op. cit., en nota 3, pág. VII. 
En ese momento nuestro Ombudsman puede representar un papel importante, poniendo ante el Tribunal Constitucional soluciones muy consensuadas, pero de dudosa constitucionalidad. Es la posición del Defensor como alternativa, como válvula de seguridad, configurado así, dijo Peces-Barba en su momento, con la autoridad que le da su condición de ponente constitucional, "por la preocupación que tenían los Constituyentes por lo restringido de esa legitimación, y para que no fuera cosa solamente de iniciados. Y se pensó en una cosa mucho más pragmática: que el Defensor del Pueblo podía abrir una vía distinta y más amplia "13. Está claro que los intereses de los sindicatos minoritarios, de los extranjeros y solicitantes de asilo, de los objetores de conciencia, o de los partidos muy minoritarios, no habrían conseguido representación ante el Tribunal Constitucional si no hubieran conseguido convencer al Defensor del Pueblo de lo legítimo de sus reclamaciones. Ya hemos dicho que éste se convierte a veces en la voz de los sin voz. Esto sucede en los casos, los más hasta ahora, en los que se presenta en solitario ante el TC para defender estas causas minoritarias. Tiene, por tanto, sentido que no lo haga cuando las mismas hayan encontrado apoyo en alguno de los otros legitimados, pues bien parece que sus facultades en este terreno deben ser usadas con mucha prudencia, "con ecuánime ponderación e imparcialidad ideológica, sin encogimiento de ánimo y con la limpia voluntad de proteger más eficazmente los derechos de los ciudadanos o de los extranjeros que reclaman su protección ${ }^{14}$.

Pero está claro que una de las finalidades de estas páginas es hacer un balance de fondo, y por ello debemos ahora cambiar de objetivo y preguntarnos, visto el problema con la perspectiva de los años pasados, básicamente dos cosas: 1) ¿para qué ha servido efectivamente la legitimación del Defensor del Pueblo ante el Tribunal Constitucional?, y 2) ¿̇en qué sectores del ordenamiento ha tenido mayores consecuencias?

No cabe duda de que la respuesta a estas dos preguntas, si es que conseguimos formularla, nos permitirá alcanzar conclusiones no demasiado irrelevantes, las propias de un artículo que pretende hacer una revisión ponderada de un problema relativamente complejo, como el que nos ocupa.

Empezando por la primera, es incuestionable que algunos recursos de inconstitucionalidad del Defensor del Pueblo han servido para expulsar del ordenamiento normas que resultaron ser contrarias a la norma suprema, y que, por tanto, no debían formar parte del mismo. Esta contribución a la depuración de nuestra normativa, en diversos sectores, no cabe duda de que es un factor que permite defender las facultades de dicha institución frente a quienes las consideran irrelevantes, inapropiadas, y peligrosas para nuestro entramado institucional. Si la mejor situación de nuestro sistema jurídico es aquella en la que no existen en el mismo normas inconstitucionales, el que

13 Intervención en Universidad Carlos III de Madrid Diez años de la Ley Orgánica del Defensor del Pueblo. Problemas y perspectivas, Dykinson, Madrid, 1992, pág 211.

14 RUIZ-GIMÉNEZ, op. cit., en nota 3, pág. VI. 
nuestro Ombudsman haya coadyuvado, aunque ya sabemos que en una medida no demasiado relevante, a esa labor de depurarlo, señalando sus problemas en ámbitos en los que nadie más que él lo había hecho, justifica sus competencias en estas materias. Los resultados no puede decirse que hayan sido verdaderamente impactantes, pero están ahí, anotándose en el haber del órgano.

La respuesta a la segunda requiere volver sobre nuestros pasos y revisar lo dicho en la parte expositiva de este trabajo. Allí vemos como un terreno en el que el Defensor del Pueblo se ha distinguido por sus éxitos en el control de la legislación inconstitucional es el de la extranjería. En el mismo ha conseguido la estimación parcial de sus pretensiones contra la primera ley de derechos y libertades de los extranjeros (STC 115/1987, de 7 de julio), que suponía, en algunos casos, una capitidisminución de aquellos, limitando sus derechos hasta unos extremos que el TC consideró, a mi juicio con acierto, inconstitucionales. Más recientemente, tuvo también éxito en el ámbito de la asistencia jurídica gratuita a los extranjeros (STC 95/2003, de 22 de mayo). Es, sin embargo, cierto que fracasó, al obtener una desestimación clara de su recurso, en su intento de que se eliminaran las reglas relativas a la "retención en frontera" de los solicitantes de asilo, y de que se les diera carácter de ley orgánica (STC 53/2002, de 27 de febrero), pero de lo que no cabe duda es que nuestro Ombudsman ha dado bastante juego en un terreno en el que, por definición, resulta complejo que los otros legitimados asuman la tarea de defensa de los derechos fundamentales de quienes son ajenos a la comunidad política española. Esta situación es la que hizo más llamativa la decisión de Enrique Múgica, actual ocupante de la institución, de no recurrir contra la segunda Ley de extranjería del año 2000, decisión que se tomó en medio de una fuerte polémica, resultó muy controvertida ${ }^{15}$, y aparece como aún más chocante desde el momento en que otras impugnaciones de la misma ley han dado lugar a unas sentencias muy críticas con la misma (SSTC 236/2007, de 7 de noviembre, 259/2007, de 19 de diciembre, y 260 a 265/2007, de 20 de diciembre). No tiene, desde luego, el Defensor del Pueblo, que poseer el don de la profecía, pero creemos que el incidente ilustra muy bien sobre los riesgos de su legitimación, y sobre cómo está claro que su resistencia a ejercerla, o el hecho de que de un paso al frente en ese sentido, provoca situaciones que pueden ser muy desagradables y conflictivas, sometiéndole a fuertes presiones.

Un ámbito en el que el Defensor del Pueblo consiguió inicialmente algunos pronunciamientos favorables, y que puede señalarse como uno de sus ámbitos típicos, puesto que en el mismo representa los intereses de quienes difícilmente podrían tener acceso al Tribunal Constitucional, es el de su bata-

15 Algunos apuntes sobre el problema en P. CARBALLO ARMAS Constitución y derechos de los extranjeros. La posición del Defensor del Pueblo en el recurso de inconstitucionalidad. (Una reflexión sobre la actuación del Ombudsman español en el caso Ley de Extranjería), en L. MIRAUT MARTín (ed.) Justicia, Migración y Derecho, Dykinson, Madrid, 2004, pags. 201 y ss. 
lla contra las diferenciaciones entre los sindicatos mayoritarios y los que no tienen tal condición. En las primeras sentencias en el tiempo (SSTC 20/1985, de 14 de febrero, 26/1985, de 22 de febrero y 72/1985, de 13 de junio) en las que el Tribunal respondió a recursos de nuestro Ombudsman, éste obtuvo un rotundo éxito, y consiguió que disposiciones presupuestarias discriminatorias, que favorecían a los más representativos, tuvieran que limitar su alcance. Más adelante, sin embargo, y en un asunto de tanta trascendencia en este terreno como el del patrimonio sindical acumulado, y su reparto, ya sabemos (STC 75/1992, de 14 de mayo) que el Defensor fracasó en su cuestionamiento, como fracasó al plantear sus objeciones a la regulación referente a la acción sindical en establecimientos militares (STC 101/1991, de 13 de mayo). Hay que recordar, también, que dos desistimientos (AATC 636/1985, de 26 de septiembre, y 812/1988, de 21 de junio) tuvieron que ver respectivamente con la intención de favorecer en Navarra a sindicatos mayoritarios, y con la colegiación obligatoria de los periodistas en Cataluña. Estos recursos, sin embargo, nos hablan de una preocupación, en algunos momentos exitosa, por mantener abiertos, frente a posibles fenómenos de anquilosamiento, los canales típicos del derecho a la libertad sindical, en donde es importante consolidar un pluralismo siempre en peligro. Puede decirse que este es otro de los campos en los que la institución ha tenido una acción constante y fundamentada, independientemente de que aquí se haya chocado con un legislador con una clara tendencia a favorecer, como pudiera en cierto modo resultar lógico para evitar fenómenos de fragmentación poco deseables, a los llamados sindicatos más representativos.

El control sobre los procesos de selección de funcionarios es otro de los asuntos que ha ocupado al Defensor, y en el que ha obtenido algunos éxitos, como la STC 31/2006, de 1 de febrero. Aquí nuestro Ombudsman se ha distinguido en la defensa de la igualdad en el acceso a los cargos públicos, y la promoción de los principios de mérito y capacidad para ello. Conectada con temas funcionariales estaba también la STC 274/2000, de 15 de noviembre, en la que ya sabemos, sin embargo, que el debate se centró en el asunto de los límites constitucionales de la legislación presupuestaria. Este terreno del acceso en condiciones de igualdad es uno de los que aparecen más apropiados para la acción del Defensor, pues la igualdad en el mismo suele ser lesionada por todo tipo de normas, apoyadas por todos los partidos políticos, tendentes a consolidar situaciones de interinidad a veces muy arraigadas, existiendo siempre la tentación de aplicar soluciones simplistas, y lesivas de los principios constitucionales, porque es mayor la presión ejercida por quienes ya tiene un puesto de trabajo, si bien precario, en la Administración, que la que pueden hacer los aspirantes, que se encuentran especialmente desprotegidos.

Uno de los recursos estrella del Defensor, que encaja perfectamente en sus funciones, fue el que tuvo por objeto la legislación de objeción de conciencia. Ya sabemos que se saldó con un rotundo fracaso (STC 160/1987, de 27 de octubre), pero eso no impide que lo pongamos aquí como un ejemplo 
de impugnación en la que ante una normativa sobre un derecho de los ciudadanos (no vamos a entrar en la polémica sobre si es un derecho fundamental o no), que resultaba más que dudosa, nuestro Ombudsman se alzó manifestando sus objeciones sobre la constitucionalidad de la misma. No logró convencer, como sabemos, a la mayoría del Tribunal Constitucional, pero sí puede decirse que el esfuerzo tenía todo su sentido, y es un buen ejemplo de una actividad que respondió claramente a lo que se esperaba de la institución. Asumió la defensa de los intereses de unos objetores que habían visto como se aprobaban unas reglas ciertamente restrictivas, en lo que fue un intento de contentar a sectores que veían con malos ojos, y consideraban peligroso, el ejercicio de aquel derecho. El Defensor intentó equilibrar dicha regulación, y, si no tuvo éxito, a pesar de los votos particulares que apoyaron algunas de sus tesis, fue por las dificultades evidentes de obtener una declaración de inconstitucionalidad que hubiera llevado al Tribunal a anular discutibles, pero legítimas, opciones del legislador democrático.

Algo parecido sucedió con los recursos en materia de libertad informática (SSTC 290/2000, de 30 de noviembre y 292/2000, de 30 de noviembre). Es este un ámbito en el que, aunque en la primera impugnación, que acabó con la apreciación, por el Tribunal, de la pérdida sobrevenida del objeto, acompañaron, como sabemos, al Defensor, las instituciones autonómicas catalanas y Diputados del Grupo Popular, en la segunda se encontró solo, defendiendo los intereses de los afectados por el manejo de los datos de carácter personal. Una soledad en la que representó perfectamente su papel consiguiendo la declaración de inconstitucionalidad de unas normas especialmente llamativas, que limitaban claramente el control sobre los propios datos que es preciso asegurar a todos los ciudadanos de acuerdo con el art. 18.4 CE. Nadie más se había alzado contra esas peligrosas realidades, y esta sentencia constituye un ejemplo de cómo, en determinados casos, puede resultar útil la polémica legitimación del Defensor del Pueblo para presentar recurso de inconstitucionalidad.

Hay otras impugnaciones en las que, sin embargo, bien parece que la intervención del Defensor del Pueblo no tiene demasiado sentido. En algunos casos existe la sospecha de que se dejó llevar por movimientos populares de cierta importancia contra normas consideradas como abiertamente injustas. Eso creemos que sucedió en el pleito que dio lugar a la STC 150/1990, de 4 de octubre, en la que se resolvió el recurso contra el recargo fiscal madrileño. $\mathrm{Al}$ parecer, fueron muchos los ciudadanos de la región que se dirigieron al Defensor, pidiéndole que parara aquella medida, y este cedió a esas presiones, aunque, como ya sabemos, también los Diputados populares la combatieron mediante su propia impugnación. Creemos que era en este terreno, el propio de la confrontación política trasladada al Tribunal Constitucional, en el que se debía resolver el problema, y que la participación aquí de nuestro Ombudsman resultaba distorsionadora. En el ámbito político es donde finalmente se dio una solución al mismo, con independencia de que las pretensiones ante el TC fracasaran con cierto estrépito. 
Otro supuesto dudoso es el de la STC 45/2007, de 1 de marzo, en el que la defensa de los intereses de determinados municipios, los que habían aumentado de población después del censo de 1991, parece una materia impropia del Defensor del Pueblo, porque esta lucha contra una posible injusticia no deja de ser también una toma de partido excesivamente clara en un problema que afecta a gran cantidad de entes locales, y cuyas soluciones siempre perjudican a algunos de ellos. Este es un tema, el de la participación en los tributos del Estado recordamos, en el que suele haber ganadores y perdedores, en términos puramente económicos, y ponerse al lado de unos, desconociendo los intereses legítimos de los otros, no parece la actitud lógica en una institución que debiera tentarse la ropa antes de hacer explícitas esas opciones, siempre discutibles.

Afirmaciones tan tajantes no se pueden hacer en el caso del sistema electoral canario (STC 225/1998, de 25 de noviembre), en el que el Defensor del Pueblo parece asumir la representación de las fuerzas políticas minoritarias, con escasa implantación en la Comunidad Autónoma en su conjunto, pero suficientemente significativa en las diferentes islas. La barrera electoral impuesta por el Estatuto de Autonomía las eliminaba, y no tenían más posibilidad que la de involucrar al Defensor del Pueblo para combatir la normativa. Es evidente que tras el recurso había unos intereses muy concretos, y en este sentido pudiera resultar criticable que nuestro Ombudsman se plegara a los mismos, pero también lo es que el tema de las limitaciones al ejercicio del derecho al sufragio es uno que trasciende determinadas circunstancias concretas, y en el que forzar pronunciamientos del Tribunal Constitucional contribuye a aclarar los fundamentos del sistema constitucional. Siempre es bueno para éste que, en aquellas situaciones, en las que se plantean en la práctica asuntos de los que se pudieran extraer enseñanzas generales, se haga posible una decisión del TC de esas que orienten sobre cuáles son las pautas de interpretación de nuestra norma constitucional que pueden considerarse correctas.

No se pueden cerrar estos razonamientos sin hacer una valoración de las dos impugnaciones, sobre el Estatuto de Cataluña y la ley del Sindíc de Greuges, a las que hicimos referencia, aunque en ninguna de ellas haya recaído todavía una decisión del Tribunal Constitucional. El Defensor del Pueblo ha entrado sin reservas, y de lleno, en el agrio debate sobre la constitucionalidad de esta normativa, debate que se está convirtiendo en uno de los más complicados, y profundos, de la ya no tan corta trayectoria de nuestro sistema constitucional. Cabe entonces preguntarse por la funcionalidad de dicha intervención. Ya dijimos más arriba que la deriva que se deducía de la misma nos parece preocupante, y vamos a detenernos un poco más en esta afirmación.

Resulta difícilmente discutible que el Defensor del Pueblo haga uso de su legitimación para dos cosas: por un lado, para cuestionar la regulación de los derechos en el Estatuto que le parezca inadecuada, derechos lingüísticos incluidos, pues esta es su materia de acción preferente, y además, es indudable 
que dicha norma presenta algunos aspectos muy polémicos en estas materias; por otro lado, para defender su propia posición institucional, puesto que las limitaciones a la misma son, en fondo, limitaciones a las garantías de los derechos fundamentales, de modo que las impugnaciones de la ley del Sindíc de Greuges, y a las reglas del Estatuto que pretenden simplemente expulsarle del territorio catalán, aparecen, independientemente de cual pueda ser su resultado final, sobre el que no vamos a hacer predicciones, como correctas, y basadas en un entendimiento sano de cual es el sentido de su legitimación, y como debe emplearla para defender su estatus constitucional.

En lo que no estamos de acuerdo, aún siendo conscientes de que la actitud del Defensor del Pueblo viene avalada por una constante jurisprudencia constitucional a la que ya hemos hecho referencia varias veces, es en que la institución haya hecho uso de sus facultades para impugnar prácticamente todo el resto del contenido del Estatuto; y ello porque se enfrenta así innecesariamente, él que debiera mantener una actitud de relativa neutralidad que facilitara el ejercicio de sus funciones, a un sector muy significativo de la sociedad catalana y española (no se olvide que el Estatuto es, al fin y al cabo, una ley orgánica estatal, aprobada por la mayoría absoluta del Congreso de los Diputados) que ha dado su apoyo a esta norma. Simplemente, creemos que este órgano debió haberse limitado a impugnar los aspectos que inciden en su ámbito de competencias, y no a representar un papel de justiciero universal para el que nos parece que no está preparado. Otros han asumido la tarea de combatir el Estatuto en su conjunto, fundamentalmente los Diputados del Grupo Popular, porque a ellos es a quienes corresponde hacer este tipo de recursos que prolongan en el TC un debate político especialmente enconado, esta vez, eso sí, con argumentos de constitucionalidad/inconstitucionalidad. El Defensor debiera moderar sus frenesís impugnadores, y cultivar una imagen de distanciamiento que le permita abordar otras tareas no menos importantes. El del Estatuto de Autonomía catalán es un buen ejemplo de cómo, por entender de una manera demasiado amplia sus facultades, nuestro Ombudsman va a perder mucho más de lo que pueda ganar.

\section{CONCLUSIÓN. UN BALANCE DE LA LEGITIMACIÓN DEL DEFENSOR DEL PUEBLO ANTE EL TRIBUNAL CONSTITUCIONAL}

En su momento, y en un análisis preferentemente teórico de la legitimación del Defensor del Pueblo para plantear recursos de inconstitucionalidad hablamos de "errónea regulación" ${ }^{16}$. En el caso de la facultad de plantear recursos de amparo afirmábamos que nos asaltaban "ciertas perplejidades" ${ }^{17}$. He-

16 La legitimación en los procesos..., op. cit., en nota 2, pág 48.

17 Ibidem, pág 224. 
cho el repaso a la práctica que acabamos de cerrar, creemos que sólo haría falta matizar ligeramente lo dicho en aquel momento.

En cuanto al recurso de amparo la legitimación se ha demostrado perfectamente inútil, como lo demuestra una práctica tan escuálida que no justifica la permanencia de las correspondientes normas. Algo dijimos sobre las razones de esa situación y, desde luego, dos sentencias, y un auto de desistimiento, desde que funciona el TC, no parecen un historial demasiado brillante para una previsión de la que probablemente se esperara mucho más. En los dos casos en los que el Tribunal ha respondido positivamente a las impugnaciones del Defensor del Pueblo, además, las mismas podían haber sido perfectamente asumidas por los interesados legítimos. El resultado hubiese sido, probablemente, el mismo.

Por lo que respecta al recurso de inconstitucionalidad, hay que reconocer que los resultados, si bien no especialmente brillantes, y susceptibles de ser calificados de más bien escasos, están ahí, con algunas declaraciones de inconstitucionalidad que no se hubieran producido sin la intervención del Defensor del Pueblo. La pregunta debe ser, por tanto, de coste/beneficio. ¿Ha merecido verdaderamente la pena habilitar a nuestro Ombudsman para recurrir, o el sistema podía haber funcionado perfectamente sin dicha atribución de facultades, evitándose además ciertas tensiones, también para este órgano? En nuestra opinión, tras repasar los resultados de la misma, la legitimación ha traído más problemas que soluciones, y nuestro régimen constitucional podría funcionar perfectamente sin ella, en el bien entendido de que uno de los mayores beneficiados sería el Defensor mismo, que podría dedicarse cuerpo y alma a la que ha sido su función en todo nuestro entorno democrático: la de solucionar los casos de incorrecto funcionamiento de la Administración Pública en sus relaciones con los ciudadanos. Quizás todo ello provenga de un diseño constitucional inapropiado, comenzando por una denominación demasiado grandilocuente. Esos delirios de grandeza pudieron corregirse en su momento, con una interpretación modesta de nuestra norma suprema. No se hizo así, y las consecuencias son las tensiones a las que se ve sometida frecuentemente la institución, tensiones que devalúan su imagen como defensor de los derechos fundamentales, imagen que es la que debiera dedicarse a cultivar para encontrar su sitio en los futuros desarrollos de nuestro Estado constitucional.

Title: Actions of the Spanish Ombudsman before the Constitutional Court. A review.

ABSTRACT: The article deals with the results of the standing of the Spanish Ombudsman in order to bring actions of constitutionality, and those to defend human rights, before the Constitutional Court. After a complete review of the decisions of this Court, in which, some way or another, the Ombudsman has taken part, a critical reflection is made on the influence this institution has exerted through these tools, and what the consequences have been for the constitutional system as a whole. 
RESUMEN: El artículo procede a repasar los resultados obtenidos como consecuencia de la legitimación del Defensor del Pueblo, en la normativa española, para interponer recursos de inconstitucionalidad y recursos de amparo ante el Tribunal Constitucional. Tras una exposición detallada de las sentencias, y autos, de este Tribunal, en los que, de una manera u otra, ha participado el Defensor del Pueblo, se hace una reflexión crítica sobre cuáles han sido la influencia ejercida por el mismo a través de estos instrumentos, y las consecuencias que ha tenido su actuación para el sistema constitucional en su conjunto.

KeY WorDs: Spanish Ombudsman; Actions; Constitutional Court; Standing.

Palabras Clave: Defensor del Pueblo; Recursos; Tribunal Constitucional; Legitimación.

FECHA DE RECEPCIÓN: 07.06.2010. FECHA DE ACEPTACIÓN: 28.07.2010. 